\title{
Toilet training: methods, parental expectations and associated dysfunctions
}

\author{
Denise M. Mota, ${ }^{1}$ Aluisio J. D. Barros ${ }^{2}$
}

\begin{abstract}
Objective: To review both the scientific literature and lay literature on toilet training, covering parents' expectations, the methods available for achieving bladder and bowel control and associated morbidities.

Sources: Articles published between 1960 and 2007, identified via the MEDLINE, Cochrane Collaboration, ERIC, Web of Science, LILACS and SciELO databases plus queries on the Google search engine; a search of related articles, references of articles, by author and of pediatrics societies. A total of 473 articles were examined and 85 of these were selected for this review.
\end{abstract}

Summary of the findings: Parents have unrealistic expectations about the age at which diapers can be withdrawn, not taking child development into account. Toilet training strategies have not changed over recent decades, and in the majority of countries the age at which children are trained has been postponed. Training methods are rarely used. Starting toilet training prematurely and stressful events during this period can extend the training process. Children who have not been trained correctly present with enuresis, urinary infection, voiding dysfunction, constipation, encopresis and refusal to go to the toilet more frequently. Literature intended for lay parents is both abundant and adequate, available in book form and on the Internet, but it is not widely available to the Brazilian population. Just three international pediatrics societies have published guidelines on toilet training.

Conclusions: Toilet training is occurring later in the majority of countries. The training methods that exist are the same from decades ago and are rarely used by mothers and valued little by pediatricians; incorrect training can be a causative factor for bladder and bowel disorders, which in turn cause problems for children and their families.

J Pediatr (Rio J). 2008;84(1):9-17: Toilet training, enuresis, child, urinary tract infection, elimination disorders.

\section{Introduction}

Toilet training is a developmental milestone and is a challenge to parents and children. It is one of the first steps that children take to become self-sufficient. All children will manage to acquire the necessary control eventually, but the difficulty involved is a major concern for parents and causes conflicts within the family. ${ }^{1}$

Toilet training is influenced by physiological, psychological and sociocultural factors. The child's first point of reference is the family, followed by enrollment at school or in daycare. There are few issues in the area of child development that involve greater concern than subjects related to toilet training and its disorders. ${ }^{2}$ Successful toilet training is good for parents and for children. The majority of parents, even those who are better informed, have inappropriate expectations with relation to the age at which toilet training should be completed. ${ }^{3,4}$

A child can be considered toilet trained when no longer requires help or supervision to use the toilet (or potty). He or she can take responsibility for independent toilet use and has the ability to keep him/herself clean and dry, i.e., not wetting or soiling their pants. ${ }^{5} \mathrm{~A}$ child is completely trained when able to be conscious of his or her own need to eliminate urine and stools and can initiate the act without being reminded or prepared by parents. ${ }^{5}$

1. Mestre. Médica nefrologista pediátrica, Programa de Pós-Graduação em Epidemiologia, Universidade Federal de Pelotas (UFPel), Pelotas, RS, Brazil.

2. Doutor. Professor associado, Programa de Pós-Graduação em Epidemiologia, UFPel, Pelotas, RS, Brazil.

No conflicts of interest declared concerning the publication of this article.

Manuscript received Oct 16 2007, accepted for publication Nov 212007.

Suggested citation: Mota DM, Barros AJ. Toilet training: methods, parental expectations and associated dysfunctions. J Pediatr (Rio J). 2008;84(1):9-17.

doi:10.2223/JPED.1752 
Toilet training itself is complex and is accomplished in steps. Acquisition of the independence necessary to use the toilet includes: walking to the toilet or potty, sitting on it, urinating or evacuating, pulling pants down and back up, flushing, washing hands and returning to the original location. Being "ready" for this stage is important to make it more enjoyable and of shorter duration. Acquiring autonomy to use the toilet requires that the child has mastered not just language, but also motor, sensory, neurological and social skills. Climate, culture and access to disposable diapers are important factors in starting toilet training. ${ }^{6-8}$ The temperament of each child also has an influence on this training. ${ }^{9}$

Different cultures have different methods of toilet training and distinct expectations about when bladder and bowel control should be achieved. The strategies employed to achieve this control have changed over the last 60 years: training now starts later, regular times for urination have been abandoned and the regular toilet seat without adapter and step stool to support the feet is being used instead of a potty. ${ }^{1,10}$

Recent studies have identified incorrect toilet training as being predictive of persistent urinary symptoms, such as urinary incontinence, enuresis, recurrent urinary tract infection and childhood constipation. ${ }^{11-14}$ The term dysfunctional elimination syndrome was introduced by Koff \& Jayanathi to described the association between voiding and intestinal dysfunction. Although well-known, its precise mechanisms remain unexplained. ${ }^{15}$

This article reviews the scientific literature on the theme, covering parents' expectations, methods available and methods actually used to achieve urinary and intestinal continence (toilet training) and also associated morbidities. The section on literature for parents is based on a review of sites on the Internet, best-selling books on the subject and parent associations.

\section{Literature review}

The search strategy for the literature review included the following databases: MEDLINE/PubMed, Cochrane Central Register of Controlled Trials, ERIC (Educational Resources Information Center), Web of Science, LILACS, SciELO and Google. Additionally, searches were run for related articles, article references and by relevant authors. The Internet sites of international pediatrics societies in several countries were also browsed in a search for guidelines on the subject. This last search identified just three sets of guidelines: published by the American Academy of Pediatrics (http:// www.aap.org/), the Canadian Paediatric Society (http:// www.cps.ca/) and the American Academy of Family Physicians (http://www.aafp.org/).

Prospective and retrospective cohort studies, crosssectional studies, case-control studies and clinical trials were included. Articles were selected on the basis of their titles and abstracts. The chosen outcomes were bladder and bowel control, training methods and associated morbidity. The searches used combinations of the following keywords: toilet training, potty training, development and toilet training, toilet training and enuresis, toilet training and dysfunction elimination syndrome, toilet training and constipation, toilet training and encopresis, toilet training and urinary tract infection, toilet learning, toilet conditioning, toilet teaching, toilet educating and toilet behaviors, resulting in the identification of a total of 735 articles.

After limiting searches to articles in French, English or Spanish, and on normal children from zero (neonates) to 19 years of age, 484 articles remained. Of these, 150 articles on the treatment and diagnosis of constipation, encopresis or enuresis were excluded, plus 64 articles on toilet training children with special needs; 49 articles on malformations of the urinary and intestinal tracts; 100 articles unrelated to the subject and 37 articles with no abstract and unrelated titles. The remaining 85 articles were read in full and included in this review article.

Many articles were repeated, with different keywords. Some publications were about the same groups of children, but discussed different outcomes. Duplicate articles were excluded together with articles with no abstract and titles unrelated to the subject under review. The criteria employed to assess the articles' methodology were those described by Downs \& Black. ${ }^{16}$ The review covered the period from 1960 to August of 2007.

Searches were also run to locate Internet resources aimed at parents, primarily using Google, and many sites were identified.

\section{Parents' expectations}

We should point out that parents' opinions and concerns relating to their children have an influence on the rhythm of the child's development and on behavior; beliefs also have an important influence on parent-child interaction and, consequently, on child development. Realistic and appropriate expectations are associated with positive interaction between parents and child and facilitate child development. In contrast, unrealistic expectations can have adverse consequences (frustration, punishment, negligence, abuse and lack of stimulation). ${ }^{3}$ Many children are forced to try to learn when they do not yet have the necessary biological conditions, causing frustration for parents and grandparents and disappointment for school teachers with rigid, inflexible demands with relation to children's mictional and intestinal habits.

Chronological age is considered a "magic moment" for starting to remove diapers, and the preference is to start before 24 months, especially before 18 months. ${ }^{17}$ A recent study based on the 12-month home visits paid to the Pelotas 
2004 Birth Cohort, demonstrated that the majority of parents exhibit unrealistic expectations of the age for toilet training and don't take into consideration the stage of development or readiness skills needed for this training. Around $70 \%$ of mothers expected their children to be trained by 18 months; $5.6 \%$ cited some type of ability acquired by the child as a parameter to indicate that toilet training should be initiated and $53 \%$ of mothers decided to take their children out of diapers based on the child's age. ${ }^{18}$ Despite these expectations, when the same cohort was visited at 24 months, just $25 \%$ of children were out of diapers during the day and $9.5 \%$ at night (unpublished observation). It is important to bring this subject up with families, since the correct guidance can help prevent family conflicts between parents and child. ${ }^{4,19}$

Other factors that should be considered are the differences between the opinions and the expectations of parents, daycare staff and doctors. Many daycare centers that accept children still in diapers train them intensively during their educational activities, contrasting with the attitudes of parents at home. This difference in opinions and instructions confuses the children, since they receive conflicting messages and do not know whose instructions to follow. ${ }^{17}$

There are few articles on parents' expectations of toilet training and the theme is generally dealt with as part of an overall assessment of child development topics. The majority of articles employ samples of convenience, in which parents are interviewed while seeking care at clinics. This being the case, generalizations can not be applied to populations of children from specific areas.

\section{The evolution of training strategies}

At the start of the twentieth century, the predominant attitude with relation to toilet training was permissiveness, changing to strictness during the $1930 \mathrm{~s} .{ }^{20}$ Parents were advised to train their children as early as possible, in order to free them from the obligation of changing diapers. ${ }^{5}$ As clinical evidence evolved, reports emerged suggesting that development of bladder and bowel control is a process of maturation that should not be accelerated, but should be left until the child manifests interest in being trained. In 1950, parents were not interfering with training and children's toilet behavior was observed, without the punishments of previous years. ${ }^{21}$ In 1962, Brazelton observed a very high prevalence of enuresis and proposed a training strategy to attempt to change this prevalence, following the guidelines laid down by Spock, still followed today, with minor adaptations and changes to the age at which training is started. ${ }^{22,23}$ This strategy is based on "passive" guidance in which, in addition to the child's physiological maturity, training should be delayed until the child demonstrates interest and the psychosocial ability to start training. It was designed to minimize conflict and anxiety and emphasize the importance of flexibility. Training should be carried out in a relatively gentle manner and with confidence that the child will learn to go to the bathroom alone, at the right time. ${ }^{24}$ In 1971, Azrin \& Foxx ${ }^{25}$ developed a rapid training system for children with disabilities and difficulties with toilet training. This method was later used with normal children. The method is based on the principles of conditioning and imitation, ${ }^{26}$ with a more intensive and structured approach.

A third, little-known method is early elimination training (assisted training). This method starts during the first weeks of life, employing a strategy of observation of the signs of elimination emanating from the baby. Once these signals have been recognized by the mother (or carer), the baby is placed on the potty to eliminate, while held by the mother/carer. This system is currently used by some communities in China, India, Africa, South and Central America and parts of Europe. ${ }^{27}$

Another method mentioned is that of Spock, which appeared before Brazelton's, being similar in that the child is not forced. There are no scientific reports of the application of these last two methods. ${ }^{28}$

There are no studies that compare toilet training methods with each other, just some clinical trials comparing the same method with different approaches. ${ }^{29,30}$ Because of this, it is difficult to assess which is the best method to use. When we evaluate toilet training it is important to define what one defines as trained, i.e. whether the child is merely able to remain dry or whether, in addition to this, they are also able to use the bathroom with autonomy. The majority of articles do not go on to define autonomy.

\section{Epidemiology of toilet training}

In the great majority of countries the age at which toilet training takes place is increasing. ${ }^{31}$ In the United States a tendency has been observed for the age at which bladder and bowel control are achieved to increase: in $1947,{ }^{20} 60 \%$ of children were trained at 18 months and $95 \%$ at 33 months; in $1962,{ }^{22} 26 \%$ at 24 months and $98 \%$ at 36 months; in $1974,{ }^{20}$ $59 \%$ at 33 months and; in 1977, 78\% at 36 months. In 1980, the mean toilet trained age varied from 25 to 27 months and, in 2003, it had increased to 36.8 (standard deviation $=6.1$ months). ${ }^{32}$ Parents expect to start training later: more than $95 \%$ before 24 months in 1970, 73\% before 29 months in 1985 and $65 \%$ before 30 months in $1996 .^{1,4,33}$

In Brazil the same tendency to delay training is being observed. Based on a cross-sectional study carried out in 2003 with children born between 1994 and 2000, the mean age at which daytime bladder and bowel control was achieved was 22.6 months, while, at 24 months, $97.6 \%$ of the children had daytime control and $89.9 \%$ nighttime control. ${ }^{34}$ In 2006, the data from the children in the Pelotas 2004 cohort indicated that, at 24 months, just $24.1 \%$ of the children had daytime control and $8.5 \%$ nighttime control, a prevalence of control that is four times lower during the day and 10 times lower during the night (unpublished observations). 
In Sweden, Hallgren observed that $92 \%$ of children had daytime urinary control at 4 years. Almost 50 years later, Jansson reported that $50 \%$ of the children had daytime control at 3.5 years - which also suggests an increase in the age at which control is achieved. The same author observed that, since the introduction of disposable diapers and the acceptance that children will decide when they are ready to become continent, the age of initiating training has been increasing, and bladder and bowel control has come to be seen as a stage of maturation. ${ }^{35,36}$

In 2002, Wong carried out a validation study on a test of development to be used with Chinese children and detected that these children exhibited a median independent control age of 54 months, with this control being defined as bladder and bowel control, with trips to the bathroom as needed and without reminders from parents. ${ }^{37}$

\section{Factors that can affect training}

Learning bladder and bowel control is based on two processes: training by parents, who teach the child where and how to urinate and pass stools and learning by the child, not just the appropriate behavior, but also to recognize their body's signals how to control release and retention by sphincters. ${ }^{38}$ It should be stressed that each child exhibits an individual rhythm of development.

In turn, certain factors can affect acquisition of bladder and bowel control, such as sex, race, cultural factors, age at start of training, prior failed attempts, stressful events in the children's lives (birth of siblings, separation of parents, moving house) and the child's temperament. ${ }^{39,40}$

Girls generally mature earlier than boys, particularly in terms of skills related to socialization (speaking, dressing and undressing, following orders) and start and complete toilet training earlier. ${ }^{1,6,8,41}$ The fact that boys are taught to use the toilet in two different ways in order to urinate and to pass stools (standing and sitting) may be one of the factors that make their learning slower. ${ }^{8}$ Similarly, cultural factors limit acceptance of the guidance that boys should first be taught to urinate sitting, which would eliminate this duality in their toilet training. 6

The social context and aspects of the culture in which the child lives contribute to the way they are cared for, both by family members and daycare staff and by health professionals. ${ }^{10,42}$ Poorer mothers who have spent less time in education start training earlier, ${ }^{43}$ as do younger mothers, ${ }^{18}$ basing the decision purely on the age of the child, without giving importance to their development. Knowledge on the subject is greater among mothers in more favorable economic situations.

Based on a radically different concept, mothers in some African tribes start to train their children from 2 to 3 weeks of life and expect them to be trained by 5 months. The cultural context also emerges when we see that African American children initiate and complete training, on average, earlier (a mean of 21 and 30 months for starting and completing, respectively) when compared with white children in the United States (30 and 39 months). These parents' expectations are different with relation to the age of this control. ${ }^{3}$ Mothers in less developed countries also expect their children to be trained at earlier ages, when compared with developed countries.

Training is considered premature when initiated before the necessary skills are present (generally around 18 months) and late when these abilities are already present, but training has not been initiated (generally around 36 months). Early toilet training can have a negative influence on acquisition of bladder and bowel control, particularly when prior training has been attempted without success, frustrating parents and child. ${ }^{26,44,45}$ On the other hand, late training may result in an increased risk of infectious diseases (diarrhea) among children in daycare, ${ }^{46}$ and also an increase in the prevalence of symptoms of voiding dysfunction, ${ }^{47}$ constipation and refusal to go to the toilet.

Stressful situations and events in the lives of children can make them regress to earlier stages of development. Children who have already acquired control may go back to urinating and passing stools in inappropriate places and children still being trained may take longer to acquire control. A child's temperament is also a factor in this training. Children who have problems following orders, whose interactions with their parents are problematic, or who are stubborn and prone to tantrums may not wish to collaborate with the stages of this training.

On the other hand, hyperactive children may not be able to remain seated long enough to wait for elimination.

\section{Problems related with training}

Normal lower urinary tract function is the result of integration of neurological pathways at the peripheral and central levels. Although the cerebral circuits involved in controlling lower urinary tract function are automatic, control of the bladder under low pressure and emptying of the bladder are under voluntary control, which may or may not be adequately controlled by the child, depending on how toilet training has been carried out.

\section{Voiding dysfunction}

It has been observed that the prevalence rates of symptoms of voiding dysfunction have been increasing, ${ }^{10,48}$ but the causes of bladder instability are as yet unknown. Symptoms of voiding dysfunction are very often ignored by parents, since they believe that they are part of their children's habits (waiting until the last minute before urinating, wetting pants, resisting the urge to urinate while involved in other activities). 
Control of the pelvic floor is voluntary and, together with the urethral sphincter, it has an important role in mictional dysfunctions of childhood. ${ }^{12}$ Repeated contraction of the pelvic floor in order to avoid urinary incontinence also leads to contraction of the urethral sphincter. As the immature bladder (neonatal) undergoes transition to mictional control, there is a risk that symptoms of voiding dysfunction may emerge. This risk increases if the transitional period is prolonged, started late or if urinary habits and positions are incorrect. 49,50

Positions that are inappropriate for bladder emptying occur when a potty that is too low is used, resulting in a "squatting" position, which creates pressure during micturition. ${ }^{51,52}$ On the other hand, a standard adult toilet, with no adapter seat (potty seat), motivates the child to contract their thigh muscles and not to relax the perineal musculature, making bladder emptying more difficult. This being the case, the ideal solution is to use a potty seat and a support for the feet (step stool) $)^{53,54}$ or a potty chair that is the correct size for the child.

Constant contraction of the pelvic floor and the sphincter does not allow the floor to relax sufficiently during micturition, leading to residual urine remaining. When this situation is repetitive, the result is reflux of bacteria from the urethra to the bladder, causing recurrent urinary infections. Several different studies have confirmed that girls with voiding dysfunction have an increased risk of recurrent urinary infections ${ }^{11,55,56}$ and of chronic constipation with or without soiling. ${ }^{53}$

\section{Constipation, refusal to go to the toilet and encopresis}

Elimination of stools is a complex process which involves the abdominal and pelvic musculature and the anal sphincter. It is activated when the rectum is distended by the presence of feces. After continence has been acquired, eliminations can be inhibited voluntarily by contracting the anal sphincter, in accordance with the child's will. ${ }^{57}$

The prevalence of childhood constipation varies depending on age, with prevalence rates having an inverse relationship with age, and varying from 0.3 to $28 \% .{ }^{58}$ In addition to the factors that are known to be involved in the etiology of constipation (transition in diet, genetic predisposition, pain or difficulty when passing stools), according to some authors incorrect toilet training (premature training, difficulties with training, traumatic experiences in the bathroom) may also be related with the emergence of constipation, ${ }^{59-61}$ but no evidence of this association is available.

One in every five children will go through a period during their toilet training when they refuse to go to the bathroom. This behavior is associated with negative consequences, such as later acquisition of bladder and bowel control, maneuvers to retain feces and an increased risk of primary encopresis, and, very often, requires medical intervention. ${ }^{62-64}$
In common with voiding dysfunction, constant contraction of the pelvic floor results in contraction of the anal sphincter, resulting in incomplete emptying of the bowel, constipation and soiling. Incomplete evacuation leads to stools becoming dry and voluminous, causing pain when they are passed. This pain triggers an inhibition against relaxing the sphincter, increasing stool retention. A vicious cycle is thereby established, the initiating factor of which, in truth, remains unclear. ${ }^{38,65,66}$

For a long time it was believed that premature toilet training could result in refusal to go to the toilet. Taubman ${ }^{45,64}$ published a conflicting result, reporting that children who were late to start toilet training were more likely to refuse. Constipated children do not initiate toilet training earlier than children who are not constipated, but they do exhibit more problems with toilet training, and take longer to complete it. ${ }^{58}$ In the same study, Borowitz, reported that pain while passing stools was the cause of constipation most often cited by parents among under-2-year-olds, followed by transition from a liquid to a solid diet and from breastmilk to bottle feeding. After 2 years of age, pain while passing stools continues to be the cause most often cited by parents, followed by toilet training.

The negative connotations of feces in our culture may lead children to become ashamed of their feces, hiding themselves from adults when they pass stools. ${ }^{64,67,68}$

There is evidence that difficulty relaxing the external anal sphincter while evacuating is one of the principal factors in constipation, but this can be treated by reconditioning bowel habits - applying control techniques. For example, going to the bathroom 5 to 15 minutes after each meal benefits the gastrocolic reflex and re-conditions the intestine to a new pattern of functioning. ${ }^{69}$

\section{Enuresis}

Bedwetting has an impact on both child and family, affecting self-esteem, interpersonal relationships and performance at school. Primary enuresis is related to the presence of nocturnal polyuria, difficulties waking from sleep and reduced bladder capacity, ${ }^{70-72}$ whereas secondary enuresis is more related to urinary infections, diabetes mellitus and emotional disorders.

The capacity of the bladder increases throughout the first 8 years of life $\mathrm{e}^{70,73}$ and can be influenced by toilet training methods. ${ }^{71,74-76}$ Coercive or permissive methods of toilet training may be associated with the development of enure$\mathrm{sis}^{22,77}$ and encopresis. ${ }^{65}$ Analyzing the prevalence of enuresis according to age of acquisition of daytime urinary continence, Chiozza observed that, among children who achieved bladder and bowel control after 36 months, the prevalence of enuresis was $17.1 \%$, whereas children who achieved control before 25 months and between 25 and 36 
months had prevalence rates of 2.7 and $5.8 \%$, respectively ${ }^{78}$ suggesting that starting toilet training later may favor the occurrence of enuresis.

Certain interventions to treat enuresis employ techniques of toilet retraining and provide guidance on regularity of elimination habits. ${ }^{53,79}$

\section{What the parent-oriented literature says}

Information available in books, journals and magazines contains valuable information for the understanding of this topic, because it represents the opinions, not just of specialists, but of other social actors as well, offering a more complete view of the concepts and beliefs disseminated through society.

The international literature, for parents who are interested, have better social economic status and are able to read English, is rich in information. Parent-oriented books and videos on children of all ages are available in the bookshops of many countries, especially in the United States. For those with access to a computer, there are many websites containing information on how to proceed during this phase of development, run by entities as diverse as non-governmental children's organizations, University-based institutions from subject areas related to education, psychology, anthropology and medicine and even by the manufacturers of diapers, toys and accessories for toilet training.

Analyzing the references identified, similarities can be observed between the recommendations, following the method described by Brazelton in $1962 .{ }^{22}$ The guidelines are practical, appropriate and many of them stimulate the purchase of accessories for training. In the recommendations reviewed here, no inappropriate guidance was observed, but the literature is extremely rich and it was not possible to review all of the websites available. In Brazil however, these sites are not numerous.

\section{What pediatric societies and pediatricians recommend}

A universal schedule for toilet training cannot be defined, because each method has its own definition of the training process $^{23}$ and each culture exhibits characteristics specific to it.

The general guidelines that do exist are very important for supervising child health, but, very often, these guidelines are not followed. They consist of medical information for families about what to expect of child development, what parents can do to promote this development and the benefits of healthy habits. ${ }^{80}$ They may be provided in a variety of ways, such as group discussions, media (videos, posters) or in written form (books, folders). ${ }^{81}$ They are different from the counseling and guidance provided for specific problems. Despite their importance, these guidelines are little used by physicians during routine consultations and, when employed, not all topics are covered ${ }^{82}$ and neither are parents asked which topics they would like to discuss. ${ }^{83}$

In 1998 the American Academy of Pediatrics published the first guidelines on training methods and, in 2003, a guide to toilet training written by pediatricians which deals with methods of training, the most common doubts and difficulties, and also includes topics on enuresis. ${ }^{84,85}$ The objective of these publications was to complement information coming from pediatricians and not to substitute it. The Canadian Paediatric Society and the American Academy of Family Physicians published their guidelines in 2005, following the same method described by the American Academy of Pediatrics. The Brazilian Society of Pediatrics (Sociedade Brasileira de Pediatria) has not published guidelines on toilet training to date.

\section{Conclusions}

Although toilet training is strongly influenced by cultural variations, it is universally seen as a milestone in child development, being one of the first challenges a child faces in acquiring independence. An increase in the age at which toilet training is initiated has been observed over recent decades and we do not know the true reason. Paradoxically, parents and carers report expectations of a very early age for the start of toilet training.

Correct bladder and bowel voiding habits are important for a healthy life and good self-esteem. Urination and evacuation problems cause discomfort for children and their families, and are motives for conflicts, distress and painful experiences for families and children and also during socialization at schools, when playing with friends and performing leisure activities.

An increase has been observed in the prevalence of elimination dysfunctions (of both urine and stools), and attempts have been made to link this phenomenon to a lack of correct toilet training.

The introduction of behavioral methods for the treatment of elimination dysfunction, such as the introduction of retraining of urination and evacuation habits, has brought good results, suggesting that well conducted toilet training may prevent future problems. Despite the importance of this process, the two principal methods of toilet training described are from the middle of the last century. They have never been tested or compared with each other by means of randomized clinical trials. Even so, they are used as the basis for the recommendations of pediatric societies' guidelines and parentoriented literature.

As a result of this lack of assessment and a lack of interest on the part of pediatricians in the subject, these training methods are not often used and mothers tend to follow guidance provided by people with influence over them, such as relatives and friends or just follow their own experience in the subject, acquired during life. 
We believe that it is important that the methods that have already been proposed be reviewed, brought up to date and tested, so that we have a strategy that can be legitimately suggested to parents as the correct manner of approaching toilet training.

\section{References}

1. Schum TR, McAuliffe TL, Simms MD, Walter JA, Lewis $M$, Pupp R. Factors associated with toilet training in the 1990s. Ambul Pediatr. 2001;1:79-86.

2. Howe AC, Walker CE. Behavioral management of toilet training, enuresis, and encopresis. Pediatr Clin North Am. 1992;39:41332.

3. Pachter LM, Dworkin PH. Maternal expectations about normal child development in 4 cultural groups. Arch Pediatr Adolesc Med. 1997; 151:1144-50.

4. Stehbens JA, Silber DL. Parental expectations in toilet training. Pediatrics. 1971;48:451-4.

5. Doleys DM, Dolce JJ. Toilet training and enuresis. Pediatr Clin North Am. 1982;29:297-313.

6. Blum NJ, Taubman B, Nemeth N. Relationship between age at initiation of toilet training and duration of training: a prospective study. Pediatrics. 2003;111:810-4.

7. deVries MW, deVries MR. Cultural relativity of toilet training readiness: a perspective from East Africa. Pediatrics. 1977; 60:170-7

8. Schum TR, Kolb TM, McAuliffe TL, Simms MD, Underhill RL, Lewis M. Sequential acquisition of toilet-training skills: a descriptive study of gender and age differences in normal children. Pediatrics. 2002;109:E48.

9. Schonwald A, Rappaport L. Consultation with the specialist: encopresis: assessment and management. Pediatr Rev. 2004; 25:278-83.

10. Bakker E, Wyndaele JJ. Changes in the toilet training of children during the last 60 years: the cause of an increase in lower urinary tract dysfunction? BJU Int. 2000;86:248-52.

11. De Paepe H, Hoebeke P, Renson C, Van Laecke E, Raes A, Van Hoecke E. Pelvic-floor therapy in girls with recurrent urinary tract infections and dysfunctional voiding. Br J Urol. 1998;81 Suppl $3: 109-13$

12. De Paepe H, Renson $C$, Hoebeke P, Raes A, Van Laecke E, Vande Walle $\mathrm{J}$. The role of pelvic-floor therapy in the treatment of lower urinary tract dysfunctions in children. Scand J Urol Nephrol. 2002;36:260-7.

13. Polaha J, Warzak WJ, Dittmer-Mcmahon K. Toilet training in primary care: current practice and recommendations from behavioral pediatrics. J Dev Behav Pediatr. 2002;23:424-9.

14. Schmitt BD. Toilet training: Getting it right the first time. Contemp Pediatr. 2004;21:105-22.

15. Koff SA. Evaluation and management of voiding disorders in children. Urol Clin North Am. 1988;15:769-75.

16. Downs SH, Black N. The feasibility of creating a checklist for the assessment of the methodological quality both of randomised and non-randomised studies of health care interventions. J Epidemiol Community Health. 1998;52:377-84.
17. Ritblatt S, Obegi A, Hammons B, Ganger T, Ganger B.Parents' and child care professionals' toilet training attitudes and practices: a comparative analisys. J Res Child Educ. 2003; $17: 133-46$.

18. Mota DM, Barros AJ. Treinamento esfincteriano precoce: prevalência, características materna, da criança e fatores associados numa coorte de nascimentos. Rev Bras Saude Mater Infant. 2007; no prelo.

19. Macias MM, Roberts KM, Saylor CF, Fussell JJ. Toileting concerns, parenting stress, and behavior problems in children with special health care needs. Clin Pediatr (Phila). 2006;45:41522.

20. Martin JA, King DR, Maccoby EE, Jacklin CN. Secular trends and individual differences in toilet-training progress. J Pediatr Psychol. 1984;9:457-67.

21. Spock B, Bergen M. Parents' fear of conflict in toilet training. Pediatrics. 1964;34:112-6.

22. Brazelton TB. A child-oriented approach to toilet training. Pediatrics. 1962;29:121-8.

23. Brazelton TB, Christophersen ER, Frauman AC, Gorski PA, Poole JM, Stadtler AC. Instruction, timeliness, and medical influences affecting toilet training. Pediatrics. 1999;103:1353-8.

24. Stadtler AC, Gorski PA, Brazelton TB. Toilet training methods, clinical interventions, and recommendations. American Academy of Pediatrics.Pediatrics. 1999;103:1359-68.

25. Azrin NH, Foxx RM. A rapid method of toilet training the institutionalized retarded. J Appl Behav Anal. 1971;4:89-99.

26. Foxx RM, Azrin NH. Dry pants: a rapid method of toilet training children. Behav Res Ther. 1973;11:435-42.

27. Rugolotto $S$, Sun M, Ball T, Boucke L, de Vries M. A surging new interest on toilet training started during the first months of age in Western countries. Tech Coloproctol. 2007;11:162-3.

28. Klassen TP, Kiddoo D, Lang ME, Friesen C, Russell K, Spooner C. The effectiveness of different methods of toilet training for bowel and bladder control. Evid Rep Technol Assess (Full Rep). 2006:157.

29. Candelora K.An evaluation of two approaches to toilet training normal children. Diss Abstr Int. 1977;38(5-B).

30. Matson $\mathrm{JL}$, Ollendick TH. Issues in toilet training normal children. Behav Ther. 1977;8:549-53.

31. Michel RS. Toilet training. Pediatr Rev. 1999;20:240-5.

32. Blum NJ, Taubman B, Nemeth N. Why is toilet training occurring at older ages? A study of factors associated with later training. J Pediatr. 2004;145:107-11.

33. Seim HC. Toilet training in first children. J Fam Pract. 1989; 29:633-6

34. Mota DM, Victora CG, Hallal PC. Investigação de disfunção miccional em uma amostra populacional de crianças de 3 a 9 anos. J Pediatr (Rio J). 2005;81:225-32.

35. Hallgren B. Enuresis. I. A study with reference to the morbidity risk and symptomatology. Acta Psychiatr Neurol Scand. 1956; $31: 379-403$.

36. Jansson UB, Hanson M, Sillen U, Hellstrom AL. Voiding pattern and acquisition of bladder control from birth to age 6 years - a longitudinal study. J Urol. 2005; 174:289-93.

37. Wong SS, Wong VC. Functional Independence Measure for Children: a comparison of Chinese and Japanese children. Neurorehabil Neural Repair. 2007;21:91-6. 
38. Fleisher DR. Understanding toilet training difficulties. Pediatrics. 2004;113:1809-10.

39. Jansson UB, Sillen U, Hellstrom AL. Life events and their impact on bladder control in children. J Pediatr Urol. 2006;3:171-7.

40. Schonwald A, Sherritt L, Stadtler A, Bridgemohan C. Factors associated with difficult toilet training. Pediatrics. 2004; 113:1753-7.

41. Largo RH, Molinari L, von Siebenthal K, Wolfensberger U. Development of bladder and bowel control: significance of prematurity, perinatal risk factors, psychomotor development and gender. Eur J Pediatr. 1999;158:115-22.

42. Finney JW, Weist MD. Behavioral assessment of children and adolescents. Pediatr Clin North Am. 1992; 39:369-78.

43. Horn IB, Brenner R, Rao M, Cheng TL. Beliefs about the appropriate age for initiating toilet training: are there racial and socioeconomic differences? J Pediatr. 2006;149:165-8.

44. Luxem M, Christophersen E. Behavioral toilet training in early childhood: research, practice, and implications. J Dev Behav Pediatr. 1994;15:370-8.

45. Taubman B. Toilet training and toileting refusal for stool only: a prospective study. Pediatrics. 1997;99:54-8.

46. Pickering LK, Bartlett AV, Woodward WE. Acute infectious diarrhea among children in day care: epidemiology and control. Rev Infect Dis. 1986:539-47.

47. Bakker E, van Gool J, Wyndaele JJ. Results of a questionnaire evaluating different aspects of personal and familial situation, and the methods of potty-training in two groups of children with a different outcome of bladder control. Scand J Urol Nephrol. 2001;35:370-6.

48. Hellstrom AL. Influence of potty training habits on dysfunctional bladder in children. Lancet. 2000;356:1787.

49. Newborg J, Stock J, Wnek L, Guidabaldi J. Battelle Developmental Inventory. Itasca: Riverside Publishing; 1988.

50. Wiener JS, Scales MT, Hampton J, King LR, Surwit R, Edwards CL. Long-term efficacy of simple behavioral therapy for daytime wetting in children. J Urol. 2000;164:786-90.

51. Christophersen ER. Toileting problems in children. Pediatr Ann. 1991;20:240-4.

52. Vernon S, Lundblad B, Hellstrom AL. Children's experiences of school toilets present a risk to their physical and psychological health. Child Care Health Dev. 2003;29:47-53.

53. De Paepe H, Renson C, Van Laecke E, Raes A, Vande Walle J, Hoebeke P. Pelvic-floor therapy and toilet training in young children with dysfunctional voiding and obstipation. BJU Int. 2000;85:889-93.

54. Vasconcelos M, Lima E, Caiafa L, Noronha A, Cangussu R, Gomes $S$, et al. Voiding dysfunction in children. Pelvic-floor exercises or biofeedback therapy: a randomized study. Pediatr Nephrol. 2006;21:1858-64.

55. Hellstrom AL. Micturition habits and incontinence in 7-year-old Swedish school entrans. Eur J Pediatr. 1990;149:434-7.

56. Wan J, Kaplinsky R, Greenfield S. Toilet habits of children evaluated for urinary tract infection. J Urol. 1995;154:797-9.

57. Catto-Smith AG. 5. Constipation and toileting issues in children. Med J Aust. 2005;182:242-6.

58. Borowitz SM, Cox DJ, Tam A, Ritterband LM, Sutphen JL, Penberthy JK. Precipitants of constipation during early childhood. J Am Board Fam Pract. 2003;16:213-8.
59. Baker SS, Liptak GS, Colletti RB, Croffie JM, Di Lorenzo C, Ector $W$, et al. Constipation in infants and children: evaluation and treatment. A medical position statement of the North American Society for Pediatric Gastroenterology and Nutrition.J Pediatr Gastroenterol Nutr. 1999;29:612-26.

60. Fischer P. Early toilet training. J Fam Pract. 1990;30:262, 360.

61. Polanco I, Prieto G.Functional constipation. Semin Pediatr Gastroenterol Nutr. 1992;3:8-10.

62. Blum NJ, Taubman B, Osborne ML. Behavioral characteristics of children with stool toileting refusal. Pediatrics. 1997;99:50-3.

63. Chase JW, Homsy Y, Siggaard C, Sit F, Bower WF. Functional constipation in children. J Urol. 2004;171:2641-3.

64. Taubman B, Blum NJ, Nemeth N. Stool toileting refusal: a prospective intervention targeting parental behavior. Arch Pediatr Adolesc Med. 2003;157:1193-6.

65. Fishman L, Rappaport L, Cousineau D, Nurko S. Early constipation and toilet training in children with encopresis. J Pediatr Gastroenterol Nutr. 2002;34:385-8.

66. Griffin GC, Roberts SD, Graham G. How to resolve stool retention in a child. Underwear soiling is not a behavior problem. Postgrad Med. 1999; 105:159-61, 65-6, 72-3.

67. Shaikh N. Time to get on the potty: Are constipation and stool toileting refusal causing delayed toilet training? J Pediatr. 2004; 145:12-3.

68. Taubman B, Blum NJ, Nemeth N. Children who hide while defecating before they have completed toilet training: a prospective study. Arch Pediatr Adolesc Med. 2003; 157:1190-2.

69. van der Plas RN, Benninga MA, Taminiau JA, Buller HA. Treatment of defaecation problems in children: the role of education, demystification and toilet training. Eur J Pediatr. 1997; 156:689-92.

70. Caldwell P, Edgar D, Hodson E, Craig J. Bedwetting and toileting problems in children. MJA Practice Essentials-Paediatrics. 2005; 182:190-5

71. Hjalmas K. [Still much ignorance about the fact that children with enuresis need treatment]. Lakartidningen. 2004;101:276-80.

72. Yeung CK. Nocturnal enuresis (bedwetting). Curr Opin Urol. 2003; $13: 337-43$

73. Jansson UB, Hanson M, Hanson E, Hellstrom AL, Sillen U. Voiding pattern in healthy children 0 to 3 years old: a longitudinal study. J Urol. 2000;164:2050-4.

74. Fergusson DM, Horwood LJ, Shannon FT. Factors related to the age of attainment of nocturnal bladder control: an 8-year longitudinal study. Pediatrics. 1986;78:884-90.

75. Hjalmas K, Arnold T, Bower W, Caione P, Chiozza LM, von Gontard $A$, et al. Nocturnal enuresis: an international evidence based management strategy. J Urol. 2004;171:2545-61.

76. Sillen $\mathrm{U}, \mathrm{Hjalmas} \mathrm{K}$. Bladder function in preterm and full-term infants - free voidings during four-hour voiding observation. Scand J Urol Nephrol Suppl. 2004;215:63-8.

77. Abramovitch IB, Abramovitch HH. Enuresis in cross-cultural perspective: a comparison of training for elimination control in three Israeli ethnic groups. J Soc Psychol. 1989;129:47-56.

78. Chiozza ML, Bernardinelli L, Caione P, Del Gado R, Ferrara P, Giorgi $\mathrm{PL}$, et al. An Italian epidemiological multicentre study of nocturnal enuresis. Br J Urol. 1998;81 Suppl 3:86-9.

79. Hellstrom AL, Hjalmas K, Jodal U. Rehabilitation of the dysfunctional bladder in children: method and 3-year followup. J Urol. 1987;138:847-9. 
80. Green M, Palfrey J, Clark E, Anastasi J, Arlington V, editors.Bright Futures: guidelines for health supervision of infants, children, and adolescents. Arlinton, VA: National Center for Education in Maternal and Child Health; 2002.

81. Nelson CS, Wissow LS, Cheng TL. Effectiveness of anticipatory guidance: recent developments. Curr Opin Pediatr. 2003; 15:630-5.

82. Galuska DA, Fulton JE, Powell KE, Burgeson CR, Pratt M, Elster $A$, et al. Pediatrician counseling about preventive health topics: results from the Physicians' Practices Survey, 1998-1999. Pediatrics. 2002;109:E83-3.

83. Schuster MA, Duan N, Regalado M, Klein DJ. Anticipatory guidance: what information do parents receive? What information do they want? Arch Pediatr Adolesc Med. 2000; 154:1191-8.
84. American Academy of Pediatrics A. Toilet training. Guidelines for parents. Elk Grove Village: AAP; 1998.

85. Wolraich ML.Guide to toilet training. New York: Bantam Dell; 2003.

Correspondence:

Denise Marques Mota

General Osório, 956

CEP 96020-000 - Pelotas, RS - Brazil

Tel.: +55 (53) 3222.4356

Fax: + 55 (53) 3227.2257

E-mail: denisemmota@gmail.com 